\title{
In-hospital Mortality of Critically III Patients with Interactions of Acute Kidney Injury and Acute Respiratory Failure in the Resource-limited Settings: Results from SEA- AKI Study
}

\author{
Nattachai Srisawat ( $\sim$ drnattachai@yahoo.com ) \\ Chulalongkorn University, King Chulalongkorn Memorial Hospital
}

Win Kulvichit

Chulalongkorn University, King Chulalongkorn Memorial Hospital

Kittipon Sarnvanichpitak

Chulalongkorn University

\section{Sadudee Peerapornrattana}

Chulalongkorn University, King Chulalongkorn Memorial Hospital

\section{Somkanya Tungsanga}

Chulalongkorn University, King Chulalongkorn Memorial Hospital

Nuttha Lumlertgul

Chulalongkorn University, King Chulalongkorn Memorial Hospital

\section{Kearkiat Praditpornsilpa}

Chulalongkorn University, King Chulalongkorn Memorial Hospital

\section{Kriang Tungsanga}

Chulalongkorn University, King Chulalongkorn Memorial Hospital

\section{Somchai Eiam-Ong}

Chulalongkorn University, King Chulalongkorn Memorial Hospital

John A Kellum

University of Pittsburgh School of Medicine

\section{SEA-AKI study group}

SEA-AKI study group

\section{Research Article}

Keywords: acute kidney injury, acute respiratory failure, epidemiology, intensive care unit

Posted Date: February 3rd, 2022

DOI: https://doi.org/10.21203/rs.3.rs-1306872/v1

License: @ (i) This work is licensed under a Creative Commons Attribution 4.0 International License. Read Full License 


\section{Abstract}

Background: While the theory of kidney-lung interorgan cross-talk has been postulated for several years, their clinical outcomes and causal relationship remained unclear. Thus, our goal was to describe clinical outcomes and explore the interactions between acute kidney injury (AKI) and acute respiratory failure (ARF) in critically ill patients.

Methods: Data were retrieved from the SEA-AKI study, a multinational multicenter database of adult ICUs from Thailand, Laos, and Indonesia. AKI was defined using KDIGO criteria stage 2-3. ARF was defined by being mechanically ventilated. Patients were assigned into 6 patterns based on AKI and ARF sequence: "no AKI/ARF", "ARF alone", "AKI alone", "ARF first", "AKI first", and "Concurrent AKI-ARF". The primary outcome was in-hospital mortality of each pattern.

Results: A final cohort of 5468 patients were eligible for the analysis. The "Concurrent AKI-ARF" had the highest inhospital mortality of $69.6 \%$. The "AKI first" and the "ARF first" had in-hospital mortality of $54.4 \%$ and $53 \%$, respectively. Among patients with single organ failure, in-hospital mortality was $14.6 \%$ and $31.5 \%$ in the "AKI alone" and the "ARF alone", accordingly. In-hospital mortality was $12.4 \%$ in patients without AKI and ARF.

Conclusion: Critically ill patients with ARF and AKI are at higher risk of in-hospital death. Further analysis and experiment is suggested to better understand the nature of this relationship.

\section{Introduction}

Acute kidney injury (AKI) and acute respiratory failure (ARF) are common associated complications which independently lead to higher mortality among critically ill patients. ${ }^{1-4}$ When both conditions overlap, the incidence of in-hospital mortality is enhanced.

It has been demonstrated that AKI led to systemic fluid congestion, retention of uremic toxins, and metabolic acidosis. A subsequent increase in work of breathing would cause or worsen lung injuries. ${ }^{5,6}$ Conversely, ARF could affect gas exchange, and stimulate neurohormonal activities such as renin-angiotensin-aldosterone system, sympathetic activities, and release arginine vasopressin. These would result in salt and water retention, yet renal hypoxia and vasoconstriction. ${ }^{7,8}$ The use of mechanical ventilation could also cause right ventricular dysfunction from increased intrathoracic pressure and lead to impaired hemodynamic status, systemic and renal congestion. Moreover, the injury in either renal tubular, or alveolar cells, or biotrauma from mechanical ventilation would contribute to a release of systemic inflammatory mediators causing further injury in the other organ, as in vicious cycle. ${ }^{9-12}$

While the theory of kidney-lung interorgan cross-talk has been postulated for several years, the causal relationship remained unclear. ${ }^{13}$ During the pandemic of COVID-19 infection, more studies report strong relationship between AKI and ARF in critically ill patients with COVID-19 infection. ${ }^{14}$ However, the clinical outcomes from each patterns of simultaneous kidney and lung injuries has not been clearly demonstrated. Thus, we aimed to explore the interaction between AKI and ARF, and their clinical outcomes among critically ill patients.

\section{Methods}

\section{Patients and study design}

This was asubanalysis ofthe prospective,multicenter,multinational,observational study, Southeast Asia AKI (SEA-AKI) study. ${ }^{15}$ In brief, this studywas conducted in 23 ICUs throughout 22 hospitals from various countries across SEA region including Thailand, Laos, and Indonesia. The study sites in this study included all level of hospitals ranging from 
university hospitals, regional hospitals, and provincial hospitals. All available data from the cohort were retrieved to maximize the power and generalizability of the results. We excluded patients with prior history of end stage renal disease (ESRD) and patients who had missing important classification data i.e. daily ventilator status, daily urine output, and daily serum creatinine and hence their AKI-ARF pattern cannot be defined. The study protocol was reviewed by the Institutional Review Board at each participating site and the need for informed consent was waived. For this study, the Institutional Review Board of Faculty of Medicine, Chulalongkorn University approved the study (IRB 440/63). This study followed the Strengthening the Reporting of Observational Studies in Epidemiology (STROBE) reporting guideline. ${ }^{16}$

\section{Study outcomes}

Our primary outcome was in-hospital mortality of each AKI-ARF pattern. Secondary outcomes includedICU length of stay, hospital length of stay, total ventilator day, ventilator free day, renal recovery at discharge,the factors associated with inhospital mortalityand the factors associated withthe development of AKI after ARF and ARF after AKI.

\section{Study definitions}

We defined AKI as stage 2-3 AKI using the Kidney Disease Improving Global Outcomes (KDIGO) classification. ${ }^{17}$ Thisdefinition of AKI aimedto avoid misclassification of minor changes in renal function or influences of fluid balance. KDIGO stage $2 \mathrm{AKI}$ is defined as a 2.0-2.9 times baseline increase in serum creatinine (SCr). KDIGO stage 3 AKI is defined as an increase in SCr to $\geq 3.0$ times baseline or an increase in $\mathrm{SCr}$ to $\geq 4 \mathrm{mg} / \mathrm{dL}$. Stages were determined based on SCr and urine output(UO)data. ARF was defined based on the need for endotracheal intubation and mechanical ventilatory support for at least 24 hours. ${ }^{18-20}$ For patients with known preadmission SCr, the most recent value in the last 12 months prior to hospitalization was used as baseline SCr. For patients without preadmission SCr, baseline SCr was estimated either using the Modification of Diet in Renal Disease (MDRD) equation back calculation or the lower SCr from hospital admission, as recommended by the Acute Disease Quality Initiative. ${ }^{21}$ Pattern of AKI and ARF of each patient were categorized based on the onset of development of AKI compared to ARF. The "Concurrent AKI-ARF" was defined by the development of AKI and ARF on the same day (within 24 hours apart). The "AKI first" was defined by the development of AKI before ARF (at least 24 hours apart). The "ARF first" was defined by the development of ARF before AKI (at least 24 hours apart). The "AKI alone" was defined by the development of AKI without ARF during ICU admission. The "ARF alone" was defined by the development of ARF without AKI during ICU admission. The "no AKI/ARF" was defined by neither AKI nor ARF was observed.Renal recovery at discharge was defined by the absence of AKI by either SCr or UO criteria.

\section{Data collection}

Data were collected prospectively by using preprinted case-recordforms.Demographic data were collected on the first day of ICU admission. This included age, sex, body mass index, comorbidity diseases (hypertension, diabetes, coronary artery disease, cerebrovascular disease, malignancy, and chronic kidney disease),Acute Physiology and Chronic Health Evaluation (APACHE) II score ${ }^{22}$, Sequential Organ Failure Assessment (SOFA) score ${ }^{23}$, and principle diagnosis of ICU admission which was classified by disease system according to Internal Classification of Diseases $10^{\text {th }}$ revision coding ${ }^{24}$. All clinical and laboratory data were collected every day for the first 7 days and then weekly until day 28. Clinicaland laboratorydata comprised of serum creatinine, blood urea nitrogen (BUN), urine output,fluid balance, status of vasopressor, status of mechanical ventilation. 


\section{Statistical analysis}

Categorical data were presented as counts and percentages. Continuous data were presented as mean and standard deviation (SD) if normally distributed or median with inter-quartile range(IQR)if non-normally distributed. The Chisquareasymptotictest of independence was used to compare the proportions of different patterns of patients, whereas as Kruskal-Wallis one-way analysis of variance by ranks was used to compare continuousvariables.

Kaplan-Meier survival curves were also generatedstratified byAKI and ARFpattern.Log-rank test was used to compare survival of each pattern. Cox proportional hazards model was also done to graphically describe the covariate-adjusted survival at 14 day after ICU admission. The rationale of showing only Cox-adjusted survival curve of 14 days was to preserve constant proportional hazards assumption which was found to be violated beyond this time point.

As this was a multi-center study with centers representing clusters, multivariable logistic mixed effect regression was usedtoidentify risk factors for in-hospital mortality, AKI development after ARF, ARF development after AKI.To determine the interactions of AKI-ARF pattern and considered risk factors on in-hospital mortality, we use AKI-ARF pattern as a main effect and accounting for interactions between AKI-ARF pattern and all other risk factors.

Mixed effect model allowed us to adjust for the site specific random effect. We investigated both the random intercept and random coefficients model. Choosing the random intercept model as it had a lower Akaike's Information Criteria and therefore a lower propensity to overfit to the sample. We also run multicollinearity diagnostics as part of our modeling process, variance inflation factor above 4 was of concern. Factors with p-value below 0.20 in univariable analysis were retained in the multivariable analysis. Regression coefficients of each factor were reported as odds ratios (OR). All analysis was conducted using the R statistical package (V4.0.3, R core team, 2020) and the mixed effect modeling using the R library, Ime4. A P-value of less than 0.05 was considered to be statistically significant. To avoid false discovery of multiple pairwise comparison, Benjamini-Hochberg correction was also applied.

\section{Results}

\section{ICU characteristics}

This cohort included 6993 eligible patients from 23 centers. After excluding 270 records of ESRD patients and 1255 records of patients with missing classification data regarding mechanical ventilation status and AKI status, 5468 patients were available for the final analysis (Figure 1). The majority of the patients were from Thailand (59.4\%) followed by Laos (26.5\%), and Indonesia (14.1\%). Mixed ICU and medical ICU were the most common type of ICU in this cohort (49.8\% and $44.5 \%$ respectively). In terms of hospital types, there were 3207 patients from university hospital (58.7\%), 1109 patients from regional hospital (20.3\%), and 1152 patients from provincial hospital (21.1\%). The definitions of each hospital type were provided in the previously published study. ${ }^{25}$

\section{Patient characteristics by pattern of AKI and ARF}

Of the analyzable cases, 1392 patients had AKI (25.5\%) and 2680 patients had ARF (49\%). Of all included AKI cases, 562 had AKI stage $3(40.4 \%)$ and 830 patients had stage 2 (59.6\%) at the time of diagnosis. After categorizing patients into each pattern of AKI and ARF, the most common pattern observed was "No AKI/ARF" (N=2156,39.4\%), followed by "ARF alone" (N=1920 patients, 35.1\%), "AKI alone" ( $\mathrm{N}=632$ patients, 11.6\%), "ARF first" ( $\mathrm{N}=658$ patients, 12\%), "AKI first" (N=79 patients, 1.4\%), and "Concurrent AKI-ARF" ( $\mathrm{N}=23$ patients, $0.4 \%)$. 
The average age of the entire cohort was $59.3 \pm 8.7$ years and $41.2 \%$ were female patients. The main primary diagnosis for ICU admission were cardiovascular disease, infectious disease, pulmonary disease, and surgical-related disease. All patient baseline characteristics stratified by pattern of AKI and ARF are provided in Table 1. Regarding the etiology of AKI, sepsis and renal hypoperfusion were the leading causes of AKI across all patterns of AKI and ARF (Table S1). As for ARF, hypoxemic ARF was the most predominant type in all patterns (Table S2).

\section{Patient outcomes}

Overall in-hospital mortality of this cohort was 25.1 percent. Based on AKI and ARF pattern, "No AKI/ARF" had in-hospital mortality of $12.4 \%$ similar to $14.6 \%$ of those in "AKI alone" while "ARF alone" had mortality of $31.5 \%$. As expected, inhospital mortality was higher in patients with dual organ failure (53\% in "ARF first" and $54.4 \%$ in "AKI first"). Among those with dual organ failure, "Concurrent AKI-ARF" had higher in-hospital mortality of $69.6 \%$ than the other two groups. As shown in Figure 2, survival is also significantly different between AKI-ARF pattern with median survival time of 47 days for "ARF alone", 59 days for "AKI alone", 31 days for "ARF first", 15 days for "AKI first", and 21 days for "Concurrent AKI-ARF" ( $P=0.001$; log-rank test). Median survival time was not reached in "No AKI/ARF". The same trends observed in unadjusted analyses were also seen in the adjusted model, in that "No AKI/ARF" does best follows by "AKI alone", "ARF alone", "ARF first", "AKI first”, and "Concurrent AKI-ARF”, accordingly (Figure 3).

For secondary outcomes, both ICU and hospital length of stay rose with the increasing number of organ failure, with the median of 2 days (IQR 2-3) and 9 days (IQR 5-15) for "No AKI/ARF", 4 days (IQR 3-8) and 11 days (IQR 6-20) for "ARF alone", 3 days (IQR 2-5) and 8 days (IQR 5-14) for "AKI alone", 7 days (IQR 4-14) and 14 days (IQR 7-29) for "ARF first", 5 days (IQR 4-8) and 10.5 days (IQR 5-18) for "AKI first", and 5 days (IQR 4-7) and 9 days (IQR 5-17.5) for "Concurrent AKI$A R F$ ", respectively. There is no clinical significance in the difference of ventilator-free days between each group. Renal recovery rate was found to be lowest in "Concurrent AKI-ARF" compared to the other groups (Table 2).

\section{Factors associated with in-hospital mortality}

Multivariable binary logistic mixed effect modelling revealed AKI-ARF pattern as significant risk factors for in-hospital

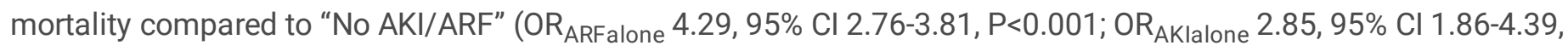
$\mathrm{P}<0.001 ; \mathrm{OR}_{\text {ARFfirst }} 13.45,95 \% \mathrm{Cl} 9-20.1, \mathrm{P}<0.001$; OR AKIfirst $_{10.91,95 \%} \mathrm{Cl} 5.43-21.9, \mathrm{P}<0.001 ; \mathrm{OR}_{\text {Concurrent }} 16.1,95 \% \mathrm{Cl}$ 6.81-42.2, $\mathrm{P}<0.001$. Other statistically significant risk factors associated with in-hospital mortality were non-surgical ICU admission, increasing APACHE II score, use of vasopressor, and fluid overload (Table 3).

To explore whether risk factors for in-hospital mortality would change between patterns of AKI and ARF, separate multivariable logistic regression models were built for each of the pattern of AKI and ARF pattern (Table S3). We also discovered significant interactions between patterns of AKI and ARF and the other risk factors on in-hospital mortality including hospital type and vasopressor use (Table 4).

\section{Factors associated with the development of the secondary organ failure}

Multivariable logistic regression models were also performed to explore the risk factors associated with the development of secondary organ failure i.e. secondary ARF (ARF after AKI) and secondary AKI (AKI after ARF). Table S4 compares patients with AKI alone versus those with AKI first. The risk factors for secondary ARF were fluid overload (OR 5.72, 95\% $\mathrm{Cl}$ 2.11-15.54, $\mathrm{P}=0.001)$ and maximum $\mathrm{AKI}$ stage $3(\mathrm{OR} 1.93,95 \% \mathrm{Cl} 1.09-3.41, \mathrm{P}=0.023)$, while protective factors for 
secondary ARF were medical ICU admission (OR 0.07, 95\% $\mathrm{Cl} 0.01-0.5, \mathrm{P}=0.009)$ and renal recovery $(\mathrm{OR} 0.08,95 \% \mathrm{Cl}$ 0.01-0.41, $\mathrm{P}=0.003$ ). Table S5 compares patients with ARF alone versus those with ARF first. The risk factors for secondary AKI were mixed ICU admission (OR 5.65, 95\% CI 1.42-22.46, P=0.014), medical ICU admission (OR 4.91, 95\% Cl 1.3-18.52, $\mathrm{P}=0.019)$, overweight (OR 2.08, 95\% Cl 1.53-2.81, $\mathrm{P}<0.001)$, obese (OR 1.94, 95\% Cl 1.18-3.21, $\mathrm{P}=0.009)$, vasopressor use (OR 2.78, 95\% Cl 2.15-3.59, $\mathrm{P}<0.001)$, increase of APACHE II score by 1 (OR 1.06, 95\% $\mathrm{Cl} 1.04-1.08$, $\mathrm{P}<0.001)$, and fluid overload (OR 4.01, 95\% Cl 3.04-5.29, $\mathrm{P}<0.001)$ while protective factors for secondary AKI were underweight (OR $0.63,95 \% \mathrm{Cl} 0.44-0.89, \mathrm{P}=0.01)$.

\section{Discussion}

We have displayed that the incidence of patients with either AKI or ARF in resource-limited settings were as high as $60.6 \%$ of the total ICU population, $22.9 \%$ of which had both AKI and ARF. The in-hospital mortality between different groups of patients varied from $12.4 \%$ to $69.6 \%$. (Table 2) Patients with double organ failure had much poorer outcomes than those with single organ failure, especially those with "Concurrent AKI-ARF". (Table 2, Figure 2) Our study also showed that the onset-based classification of AKI and ARF interplay has shown different risk profiles. $($ Table 3,4$)$

In our study, the in-hospital mortality rates of patients in each group were higher than those previously reported in highresource-settings. ${ }^{4,26-29}$ For example, an observational cohort by Darmon et al. showed that the in-hospital mortality of AKI with acute respiratory distress syndrome (ARDS) were $42.3 \%$. These distinct findings are probably due to the different risk associated with the resource-limited settings. One of the main factors is the delayed ICU admission which could be reflected by the earlier onset of AKI and ARF in the ICUs (median time to organ failure onset 1 day for ARF and 2 days for AKI). Among patients with single organ failure, we observed that the in-hospital mortality of "ARF alone" appeared to be higher than "AKI alone". This may be due to the higher severity of acute illness which were reflected by higher APACHE II score and SOFA score in "ARF alone". After adjusting severity scores as confounders, the adjusted odds ratio of "AKI alone" and "ARF alone" on in-hospital mortality were not statistically different (Table 3). This might imply that the definition of AKI by KDIGO stage 2 and the definition of ARF by mechanical ventilation status reflect similar mortality outcomes.

Another interesting result of our analysis is that the outcome of AKI-ARF interaction depends not only on the additive effect of the total number of organ failure but also the timing of organ failure which results in the highest in-hospital mortality among those with "Concurrent AKI-ARF". Though the higher severity of concurrent occurrence of organ failure may be confounded by the shorter time of organ failure evolution, contradicting evidence were described by Sakr et al. that the time required for ICU patients to reach the highest degree of organ failure was shorter in survivors. ${ }^{29}$ Thus, the different pattern of AKI and ARF interaction may be regarded as different clinical entity.

From our analysis, fluid overload, defined by positive fluid balance of more than $10 \%$ of the actual bodyweight, was a major independent risk factor for the development of secondary organ failure in both AKI after ARF and ARF after AKI. This finding was consistent with many studies in the past. ${ }^{30-32}$ This signifies the importance of conservative fluid management to prevent further organ failure after an occurrence of either AKI or ARF as fluid overload is a modifiable risk factor.

While higher maximum AKI staging was a risk factor for ARF after AKI, renal recovery was an independent protective factor. These results suggest that the patients with severe and/or persistent AKI are at higher risk of subsequent development of ARF. The dose-response relationship further validates the causality between AKI and ARF. Therefore, providing proper AKI management may also improve pulmonary outcomes. ${ }^{13}$ 
Unsurprisingly, vasopressor use and higher APACHE II score were both independent risk factors for AKI after ARF. Though this may merely reflect the higher severity of illness, the independent relationship between vasopressor use and AKI development after ARF may also suggest unstable hemodynamics as a pathophysiological mechanism of AKI in patients with ARF. Moreover, obesity was also found to increase the risk of AKI development after ARF. This result was corroborated by the study by Soto et al. which observed obesity as an independent risk factor for development of AKI in 751 patients with acute respiratory distress syndrome. ${ }^{33}$ However, the underlying mechanism is still yet to be elucidated.

To our knowledge, this is one of the first few studies that demonstrates the patterns of AKI and ARF and their relevance to the clinical outcomes. A key strength of our study is the large database of patients and its multicenter, including a wide coverage of population in Southeast Asia and a wide variety of ICUs. It also contains the data regarding the process of care i.e., reimbursement data and levels of hospital. This data are very important and highly relevant to the treatment decision especially in the limited-resource settings. ${ }^{34}$ Another strong point is that our AKI definition and staging adhere to the KDIGO criteria which incorporates both serum creatinine and urine output data. Furthermore, the availability of data permitted the detailed analysis of risk factors of AKI after ARF and ARF after AKI, something that has previously received little attention.

We acknowledge a number of limitations of our study. First, because the parent study, the SEA-AKI study, mainly focused on risk factors for AKI, we lack some of the important ARF-related data including the etiology of ARF, blood gas, and mechanical ventilator settings. However, a large observational study by Panitchote et al. reported that ventilator-specific variables had no impact on the development of AKI in patients with ARDS. ${ }^{27}$ Therefore, including those variables may not substantially alter the findings of our study. Second, our study covers only short-term outcomes, namely, the inhospital mortality. The longer-term outcomes still needed to be further elucidated. Third, the number of patients in "Concurrent AKI-ARF" is relatively low because most patients who simultaneously met criteria of AKI and ARF on the day of ICU admission could not be determined whether AKI and/or ARF was developed prior to the ICU admission and, hence, need to be excluded from our analysis. In the resource-limited settings, large number of patients are mechanically ventilated outside the ICUs due to short supply of ICU beds. ${ }^{35}$ Therefore, we could not determine the true onset of those who developed ARF since the first day of the ICU admission. Fourth, true prior baseline serum creatinine levels were determined only in $22 \%$ of patients and we chose the reference creatinine from the lowest value between the first serum creatinine on the day of admission and the MDRD formula assuming a GFR of at least $75 \mathrm{~mL} / \mathrm{min} / 1.73 \mathrm{~m}^{2}$. If a patient had a history of CKD, then we used the first available serum creatinine as the baseline serum creatinine, as MDRD back calculation assumes that patients do not have CKD. Lastly, the amount of urine output was recorded on the 24-hour basis. Therefore, the modified urine output criteria were used for the diagnosis of AKI. This approach would have delayed the diagnosis in some of the patients with stage $2 \mathrm{AKI}$ by urine output which may result in misclassification of AKI-ARF pattern. However, we allowed the time span of 24-48 hours between each pattern in order to compensate the risk of misclassification.

\section{Conclusion}

$\mathrm{AKI}$ and ARF are very prevalent in the ICU. The outcomes of the interaction of AKI and ARF are severe, especially in the resource-limited settings. Based on the sequence of organ failure occurrence, different patterns of AKI and ARF and their distinct clinical outcomes were identified. While the risk factors of in-hospital mortality of each pattern of AKI and ARF were almost similar, the risk factors for the development of secondary organ failure varied by the condition of the primary organ failure. Fluid optimization may be the key to prevent the development of secondary organ failure in the AKI and ARF interaction. The results of our study should foster further research into the clear understanding of lungkidney interactions in critically ill patients. 


\section{Declarations}

\section{Ethical approval and consent to participate}

The study protocol was reviewed by the Institutional Review Board at each participating site and the need for informed consent was waived. For this study, the Institutional Review Board of Faculty of Medicine, Chulalongkorn University approved the study (IRB 440/63).

\section{Consent for publication}

Not applicable.

\section{Availability of data and materials}

The datasets used and/or analyzed during the current study are available from the corresponding author on reasonable request.

\section{Competing interests}

The authors declare that they have no competing interests.

\section{Funding}

Financial support for the study was provided by International Society of Nephrology (ISN), The Kidney Foundation of Thailand and the Medical Association of Thailand.

\section{Authors' contributions}

WK, SP, NL, and NS were responsible for the study concept and design. WK, SP, NL, and NS were responsible for the data acquisition. WK and KS were responsible for statistical analysis. WK, SP, ST, NL, JK and NS were responsible for data interpretation. WK, SP, ST, NL, and NS were responsible for drafting the main manuscript. WK prepared the figures. All authors reviewed the manuscript.

\section{Acknowledgement}

Members of SEA-AKI study group include:

Nattachai Srisawat, M.D. (corresponding author), Win Kulvichit, M.D., Sadudee Peerapornrattana, M.D., Nuttha Lumlertgul, M.D., Noppathorn Mahamitra, M.D., Passisd Loaveeravat, M.D., Kearkiat Praditpornsilpa, M.D., Khajohn Tiranathanagul, M.D., Kriang Tungsanga, M.D., Somchai Eiam-Ong, M.D., Visith Sitprija, M.D. from Division of Nephrology, Department of Medicine, Faculty of Medicine, Chulalongkorn University, and King Chulalongkorn Memorial Hospital, Bangkok, Thailand;

Asada Leelahavanichkul, M.D. from Department of Microbiology, Faculty of Medicine, Chulalongkorn University, Bangkok, Thailand; 
Manasnun Kongwibulwut, M.D., Pornlert Chatkaew, M.D. from Department of Anesthesiology, Faculty of Medicine, Chulalongkorn University, Bangkok, Thailand;

Cameron Hurst, Ph.D., Stephen J. Kerr, Ph.D. from Biostatistics Excellence Centre, Research Affairs, Faculty of Medicine, Chulalongkorn University, Bangkok, Thailand;

Anan Chuasuwan, M.D. from Department of Medicine, Bhumibol Adulyadej Hospital, Royal Thai Air Force, Bangkok, Thailand;

Konlawij Trongtrakul, M.D. from Department of Medicine, Faculty of Medicine Vajira Hospital, Navamindradhiraj University, Bangkok, Thailand;

Adis Tasnarong, M.D., Pattharawin Pattharanitima, M.D. from Department of Medicine, Faculty of Medicine, Thammasat University, Bangkok, Thailand;

Ratapum Champunot, M.D. from Department of Medicine, Buddhachinaraj Hospital, Phitsanulok, Thailand;

Rangsun Bhurayanontachai, M.D. from Division of Critical Care Medicine, Department of Medicine, Faculty of Medicine, Prince Songkla University, Songkla, Thailand;

Petchdee Oranrigsupak, M.D. from Department of Medicine, Nan Hospital, Nan, Thailand;

Theerapon Sukmark, M.D. from Thungsong Hospital, Nakhon Si Thammarat, Thailand;

Thanachai Panaput, M.D. from Kon Kaen Regional Hospital, Kon Kaen, Thailand;

Natthapon Laohacharoenyot, M.D. from Sriphat Medical Center, Faculty of Medicine, Chiang Mai University, Chiang Mai, Thailand;

Karjbundid Surasit, M.D. from Nakornping Hospital, Chiang Mai, Thailand;

Thathsalang Keobounma, M.D. from Thabo Crown Prince Hospital, Nong Khai, Thailand;

Kamol Khositrangsikun, M.D. from Maharaj Nakhon Si Thammarat Hospital, Nakhon Si Thammarat, Thailand;

Ummarit Suwattanasilpa, M.D. from Mahasarakarm Hospital, Mahasarakarm, Thailand, 18Taksinmaharaj Hospital, Tak, Thailand;

Poramin Santithisadeekorn, M.D. from Taksinmaharaj Hospital, Tak, Thailand;

Anocha Wanitchanont, M.D. from Department of Medicine, Cbonburi Hospital, Chonburi, Thailand;

Jonny Jonny, M.D., Vedora Angelia, M.D., Ayu Nursantisuryani Jahya, M.D., Lydia Permata Hilman, M.D., Venna Febrian Kusumaningrum, M.D. from Division of Nephrology, Department of Internal Medicine, Gatot Soebroto Indonesia Central Army Hospital, Jakarta, Indonesia;

Moch Hasyim, M.D. from Department of Anesthesiology and Reanimation, Gatot Soebroto Indonesia Central Army Hospital, Jakarta, Indonesia;

Noot Sengthavisouk, M.D., Chanmaly Keomany, M.D. from Department of Nephrology, Division of Critical Care, Mittaphab Hospital, Vientiane Capital, Laos; 
Phonepadith Banouvong, M.D., Division of Critical Care, Luangprabang Provincial Hospital, Laos;

Phetvilay Senavong, M.D., Division of Critical Care, Savannakhet Provincial Hospital, Laos;

Sidavone Xayyaphet, M.D., Division of Critical Care, Mahosot Hospital, Vientiane Capital, Laos;

Sakountala Binbundith, M.D., Division of Critical Care, Champasak Provincial Hospital, Laos;

John A. Kellum, M.D. from Center for Critical Care Nephrology, The CRISMA Center, Department of Critical Care Medicine, University of Pittsburgh School of Medicine, Pittsburgh, PA, USA.

\section{References}

1. Srisawat N, Kellum JA. Acute kidney injury: definition, epidemiology, and outcome. Curr Opin Crit Care 2011;17:54855.

2. Susantitaphong P, Cruz DN, Cerda J, Abulfaraj M, Alqahtani F, Koulouridis I, et al. World incidence of AKI: a metaanalysis. Clin J Am Soc Nephrol 2013;8:1482-93.

3. Vincent JL, Akca S, De Mendonca A, Haji-Michael P, Sprung C, Moreno R, et al. The epidemiology of acute respiratory failure in critically ill patients. Chest 2002;121:1602-9.

4. Ostermann M, Chang RW. Impact of different types of organ failure on outcome in intensive care unit patients with acute kidney injury. J Crit Care 2011;26:635 e1- e10.

5. Li X, Hassoun HT, Santora R, Rabb H. Organ crosstalk: the role of the kidney. Curr Opin Crit Care 2009;15:481-7.

6. Husain-Syed F, McCullough PA, Birk HW, Renker M, Brocca A, Seeger W, et al. Cardio-Pulmonary-Renal Interactions: A Multidisciplinary Approach. J Am Coll Cardiol 2015;65:2433-48.

7. Hemlin M, Ljungman S, Carlson J, Maljukanovic S, Mobini R, Bech-Hanssen O, et al. The effects of hypoxia and hypercapnia on renal and heart function, haemodynamics and plasma hormone levels in stable COPD patients. Clin Respir J 2007;1:80-90.

8. Anand IS, Chandrashekhar Y, Ferrari R, Sarma R, Guleria R, Jindal SK, et al. Pathogenesis of congestive state in chronic obstructive pulmonary disease. Studies of body water and sodium, renal function, hemodynamics, and plasma hormones during edema and after recovery. Circulation 1992;86:12-21.

9. Kuiper JW, Vaschetto R, Della Corte F, Plotz FB, Groeneveld AB. Bench-to-bedside review: Ventilation-induced renal injury through systemic mediator release-just theory or a causal relationship? Crit Care 2011;15:228.

10. Ranieri VM, Giunta F, Suter PM, Slutsky AS. Mechanical ventilation as a mediator of multisystem organ failure in acute respiratory distress syndrome. JAMA 2000;284:43-4.

11. Husain-Syed F, Slutsky AS, Ronco C. Lung-Kidney Cross-Talk in the Critically III Patient. Am J Respir Crit Care Med 2016;194:402-14.

12. Rezoagli E, McNicholas B, Pham T, Bellani G, Laffey JG. Lung-kidney cross-talk in the critically ill: insights from the Lung Safe study. Intensive Care Med 2020;46:1072-3.

13. Joannidis M, Forni LG, Klein SJ, Honore PM, Kashani K, Ostermann M, et al. Lung-kidney interactions in critically ill patients: consensus report of the Acute Disease Quality Initiative (ADQI) 21 Workgroup. Intensive Care Med 2020;46:654-72.

14. Nadim MK, Forni LG, Mehta RL, Connor MJ, Jr., Liu KD, Ostermann M, et al. COVID-19-associated acute kidney injury: consensus report of the 25th Acute Disease Quality Initiative (ADQI) Workgroup. Nat Rev Nephrol 2020;16:747-64.

15. Srisawat N, Kulvichit W, Mahamitra N, Hurst C, Praditpornsilpa K, Lumlertgul N, et al. The epidemiology and characteristics of acute kidney injury in the Southeast Asia intensive care unit: a prospective multicentre study.

Page 10/19 
Nephrol Dial Transplant 2019.

16. von Elm E, Altman DG, Egger M, Pocock SJ, Gotzsche PC, Vandenbroucke JP, et al. The Strengthening the Reporting of Observational Studies in Epidemiology (STROBE) statement: guidelines for reporting observational studies. Ann Intern Med 2007;147:573-7.

17. Kellum JA, Lameire N, Aspelin P, Barsoum RS, Burdmann EA, Goldstein SL, et al. Kidney disease: improving global outcomes (KDIGO) acute kidney injury work group. KDIGO clinical practice guideline for acute kidney injury. Kidney international supplements 2012;2:1-138.

18. Hughes M, Grant IS, MacKirdy FN. Incidence and mortality after acute respiratory failure and acute respiratory distress syndrome in Sweden, Denmark, and Iceland. Am J Respir Crit Care Med 2000;162:332-3.

19. Lewandowski K, Metz J, Deutschmann C, Preiss H, Kuhlen R, Artigas A, et al. Incidence, severity, and mortality of acute respiratory failure in Berlin, Germany. Am J Respir Crit Care Med 1995;151:1121-5.

20. Vasilyev S, Schaap RN, Mortensen JD. Hospital survival rates of patients with acute respiratory failure in modern respiratory intensive care units. An international, multicenter, prospective survey. Chest 1995;107:1083-8.

21. Bellomo R, Ronco C, Kellum JA, Mehta RL, Palevsky P, Acute Dialysis Quality Initiative w. Acute renal failure definition, outcome measures, animal models, fluid therapy and information technology needs: the Second International Consensus Conference of the Acute Dialysis Quality Initiative (ADQI) Group. Crit Care 2004;8:R204-12.

22. Knaus WA, Draper EA, Wagner DP, Zimmerman JE. APACHE II: a severity of disease classification system. Crit Care Med 1985;13:818-29.

23. Vincent JL, Moreno R, Takala J, Willatts S, De Mendonca A, Bruining H, et al. The SOFA (Sepsis-related Organ Failure Assessment) score to describe organ dysfunction/failure. On behalf of the Working Group on Sepsis-Related Problems of the European Society of Intensive Care Medicine. Intensive Care Med 1996;22:707-10.

24. World Health Organization. The ICD-10 classification of mental and behavioural disorders : diagnostic criteria for research. Geneva: World Health Organization; 1993. xiii, 248 p. p.

25. Srisawat N, Kulvichit W, Mahamitra N, Hurst C, Praditpornsilpa K, Lumlertgul N, et al. The epidemiology and characteristics of acute kidney injury in the Southeast Asia intensive care unit: a prospective multicentre study. Nephrology Dialysis Transplantation 2020;35:1729-38.

26. Chertow GM, Christiansen CL, Cleary PD, Munro C, Lazarus JM. Prognostic stratification in critically ill patients with acute renal failure requiring dialysis. Arch Intern Med 1995;155:1505-11.

27. Panitchote A, Mehkri O, Hastings A, Hanane T, Demirjian S, Torbic H, et al. Factors associated with acute kidney injury in acute respiratory distress syndrome. Ann Intensive Care 2019;9:74.

28. Sweet SJ, Glenney CU, Fitzgibbons JP, Friedmann P, Teres D. Synergistic effect of acute renal failure and respiratory failure in the surgical intensive care unit. Am J Surg 1981;141:492-6.

29. Sakr Y, Lobo SM, Moreno RP, Gerlach H, Ranieri VM, Michalopoulos A, et al. Patterns and early evolution of organ failure in the intensive care unit and their relation to outcome. Crit Care 2012;16:R222.

30. Martin GS, Moss M, Wheeler AP, Mealer M, Morris JA, Bernard GR. A randomized, controlled trial of furosemide with or without albumin in hypoproteinemic patients with acute lung injury. Crit Care Med 2005;33:1681-7.

31. National Heart L, Blood Institute Acute Respiratory Distress Syndrome Clinical Trials N, Wiedemann HP, Wheeler AP, Bernard GR, Thompson BT, et al. Comparison of two fluid-management strategies in acute lung injury. N Engl J Med 2006;354:2564-75.

32. Grissom CK, Hirshberg EL, Dickerson JB, Brown SM, Lanspa MJ, Liu KD, et al. Fluid management with a simplified conservative protocol for the acute respiratory distress syndrome*. Crit Care Med 2015;43:288-95.

33. Soto GJ, Frank AJ, Christiani DC, Gong MN. Body mass index and acute kidney injury in the acute respiratory distress syndrome. Crit Care Med 2012;40:2601-8.

Page 11/19 
34. Sengthavisouk N, Lumlertgul N, Keomany C, Banouvong P, Senavong P, Sayyaphet S, et al. Epidemiology and shortterm outcomes of acute kidney injury among patients in the intensive care unit in Laos: a nationwide multicenter, prospective, and observational study. BMC Med 2020;18:1-9.

35. Brunkhorst FM, Engel C, Bloos F, Meier-Hellmann A, Ragaller M, Weiler N, et al. Intensive insulin therapy and pentastarch resuscitation in severe sepsis. N Engl J Med 2008;358:125-39.

\section{Tables}

\section{Table 1}

Baseline characteristics stratified by acute kidney injury and acute respiratory failure patterns 


\begin{tabular}{|c|c|c|c|c|c|c|c|c|}
\hline & Overall & $\begin{array}{l}\text { No } \\
\text { AKI/ARF }\end{array}$ & ARF alone & $\begin{array}{l}\text { AKI } \\
\text { alone }\end{array}$ & ARF first & AKI first & $\begin{array}{l}\text { Concurrent } \\
\text { AKI-ARF }\end{array}$ & $\begin{array}{l}\mathrm{P}- \\
\text { value }\end{array}$ \\
\hline $\mathrm{N}$ & 5468 & 2156 & 1920 & 632 & 658 & 79 & 23 & \\
\hline $\begin{array}{l}\text { Age, mean }(S D), \\
\text { years }\end{array}$ & $\begin{array}{l}59.3 \\
(18.7)\end{array}$ & $\begin{array}{l}57.6 \\
(17.9)\end{array}$ & $58.8(19.6)$ & $\begin{array}{l}60.8 \\
(18.1)\end{array}$ & $\begin{array}{l}64.5 \\
(18.0)\end{array}$ & $\begin{array}{l}60.8 \\
(17.4)\end{array}$ & $62.1(20.5)$ & $<0.001$ \\
\hline Female, n (\%) & $\begin{array}{l}2253 \\
(41.2)\end{array}$ & $\begin{array}{l}885 \\
(41.0)\end{array}$ & 748 (39.0) & $\begin{array}{l}286 \\
(45.3)\end{array}$ & $\begin{array}{l}289 \\
(43.9)\end{array}$ & 35 (44.3) & $10(43.5)$ & 0.058 \\
\hline Country, n (\%) & & & & & & & & $<0.001$ \\
\hline Thailand & $\begin{array}{l}3247 \\
(59.4)\end{array}$ & $\begin{array}{l}856 \\
(39.7)\end{array}$ & $\begin{array}{l}1355 \\
(70.6)\end{array}$ & $\begin{array}{l}390 \\
(61.7)\end{array}$ & $\begin{array}{l}586 \\
(89.1)\end{array}$ & $43(54.4)$ & $17(73.9)$ & \\
\hline Indonesia & $\begin{array}{l}772 \\
(14.1)\end{array}$ & $\begin{array}{l}446 \\
(20.7)\end{array}$ & $166(8.6)$ & $\begin{array}{l}86 \\
(13.6)\end{array}$ & $42(6.4)$ & $27(34.2)$ & $5(21.7)$ & \\
\hline Laos & $\begin{array}{l}1449 \\
(26.5)\end{array}$ & $\begin{array}{l}854 \\
(39.6)\end{array}$ & $399(20.8)$ & $\begin{array}{l}156 \\
(24.7)\end{array}$ & $30(4.6)$ & $9(11.4)$ & $1(4.3)$ & \\
\hline $\begin{array}{l}\text { Hospital type, } \mathrm{n} \\
(\%)\end{array}$ & & & & & & & & $<0.001$ \\
\hline Provincial & $\begin{array}{l}1152 \\
(21.1)\end{array}$ & $\begin{array}{l}563 \\
(26.1)\end{array}$ & $310(16.1)$ & $\begin{array}{l}162 \\
(25.6)\end{array}$ & $\begin{array}{l}108 \\
(16.4)\end{array}$ & $8(10.1)$ & $1(4.3)$ & \\
\hline Regional & $\begin{array}{l}1109 \\
(20.3)\end{array}$ & $\begin{array}{l}219 \\
(10.2)\end{array}$ & $519(27.0)$ & $\begin{array}{l}139 \\
(22.0)\end{array}$ & $\begin{array}{l}212 \\
(32.2)\end{array}$ & $14(17.7)$ & $6(26.1)$ & \\
\hline University & $\begin{array}{l}3207 \\
(58.7)\end{array}$ & $\begin{array}{l}1374 \\
(63.7)\end{array}$ & $\begin{array}{l}1091 \\
(56.8)\end{array}$ & $\begin{array}{l}331 \\
(52.4)\end{array}$ & $\begin{array}{l}338 \\
(51.4)\end{array}$ & 57 (72.2) & $16(69.6)$ & \\
\hline ICU type, n (\%) & & & & & & & & $<0.001$ \\
\hline Surgical & $\begin{array}{l}313 \\
(5.7)\end{array}$ & $148(6.9)$ & 119 (6.2) & $27(4.3)$ & $11(1.7)$ & 8 (10.3) & $0(0.0)$ & \\
\hline Mixed & $\begin{array}{l}2713 \\
(49.8)\end{array}$ & $\begin{array}{l}1409 \\
(65.7)\end{array}$ & 772 (40.3) & $\begin{array}{l}332 \\
(52.6)\end{array}$ & $\begin{array}{l}148 \\
(22.5)\end{array}$ & $43(55.1)$ & 9 (39.1) & \\
\hline Medical & $\begin{array}{l}2425 \\
(44.5)\end{array}$ & $\begin{array}{l}588 \\
(27.4)\end{array}$ & $\begin{array}{l}1026 \\
(53.5)\end{array}$ & $\begin{array}{l}272 \\
(43.1)\end{array}$ & $\begin{array}{l}498 \\
(75.8)\end{array}$ & $27(34.6)$ & $14(60.9)$ & \\
\hline $\begin{array}{l}\text { Reimbursement } \\
(\%)\end{array}$ & & & & & & & & $<0.001$ \\
\hline UC. SS & $\begin{array}{l}2547 \\
(46.9)\end{array}$ & $\begin{array}{l}773 \\
(36.0)\end{array}$ & $\begin{array}{l}1060 \\
(55.6)\end{array}$ & $\begin{array}{l}251 \\
(39.9)\end{array}$ & $\begin{array}{l}414 \\
(63.5)\end{array}$ & $40(50.6)$ & 9 (42.9) & \\
\hline Government & $\begin{array}{l}1367 \\
(25.2)\end{array}$ & $\begin{array}{l}589 \\
(27.4)\end{array}$ & 367 (19.2) & $\begin{array}{l}199 \\
(31.6)\end{array}$ & $\begin{array}{l}173 \\
(26.5)\end{array}$ & $28(35.4)$ & $11(52.4)$ & \\
\hline Self pay & $\begin{array}{l}1521 \\
(28.0)\end{array}$ & $\begin{array}{l}785 \\
(36.6)\end{array}$ & $480(25.2)$ & $\begin{array}{l}179 \\
(28.5)\end{array}$ & 65 (10.0) & $11(13.9)$ & $1(4.8)$ & \\
\hline BMI, n (\%) & & & & & & & & $<0.001$ \\
\hline Normal & $\begin{array}{l}3671 \\
(67.4)\end{array}$ & $\begin{array}{l}1549 \\
(71.9)\end{array}$ & $\begin{array}{l}1295 \\
(67.9)\end{array}$ & $\begin{array}{l}393 \\
(62.3)\end{array}$ & $\begin{array}{l}380 \\
(57.9)\end{array}$ & $41(53.2)$ & $13(56.5)$ & \\
\hline Overweight & $\begin{array}{l}974 \\
(17.9)\end{array}$ & $\begin{array}{l}392 \\
(18.2)\end{array}$ & 259 (13.6) & $\begin{array}{l}133 \\
(21.1)\end{array}$ & $\begin{array}{l}162 \\
(24.7)\end{array}$ & $25(32.5)$ & $3(13.0)$ & \\
\hline Obese & $\begin{array}{l}215 \\
(3.9)\end{array}$ & $53(2.5)$ & $66(3.5)$ & $47(7.4)$ & $44(6.7)$ & $3(3.9)$ & $2(8.7)$ & \\
\hline
\end{tabular}




\begin{tabular}{|c|c|c|c|c|c|c|c|c|}
\hline Underweight & $\begin{array}{l}589 \\
(10.8)\end{array}$ & $161(7.5)$ & $287(15.0)$ & $58(9.2)$ & 70 (10.7) & $8(10.4)$ & $5(21.7)$ & \\
\hline \multicolumn{9}{|l|}{$\begin{array}{l}\text { Comorbidity, n } \\
(\%)\end{array}$} \\
\hline Hypertension & $\begin{array}{l}2027 \\
(37.1)\end{array}$ & $\begin{array}{l}822 \\
(38.1)\end{array}$ & 651 (33.9) & $\begin{array}{l}247 \\
(39.1)\end{array}$ & $\begin{array}{l}265 \\
(40.3)\end{array}$ & $32(40.5)$ & $10(43.5)$ & 0.016 \\
\hline DM & $\begin{array}{l}1217 \\
(22.3)\end{array}$ & $\begin{array}{l}485 \\
(22.5)\end{array}$ & $363(18.9)$ & $\begin{array}{l}172 \\
(27.3)\end{array}$ & $\begin{array}{l}160 \\
(24.4)\end{array}$ & 31 (39.2) & $6(26.1)$ & $<0.001$ \\
\hline CKD & $\begin{array}{l}356 \\
(6.5)\end{array}$ & $127(5.9)$ & $75(3.9)$ & $\begin{array}{l}97 \\
(15.3)\end{array}$ & $46(7.0)$ & $9(11.4)$ & $2(8.7)$ & $<0.001$ \\
\hline CAD & $\begin{array}{l}384 \\
(7.0)\end{array}$ & $118(5.5)$ & $126(6.6)$ & $\begin{array}{l}67 \\
(10.7)\end{array}$ & $66(10.1)$ & $5(6.3)$ & $2(8.7)$ & $<0.001$ \\
\hline CVD & $\begin{array}{l}215 \\
(3.9)\end{array}$ & $58(2.7)$ & $84(4.4)$ & $25(4.0)$ & $46(7.0)$ & $2(2.5)$ & $0(0.0)$ & $<0.001$ \\
\hline Malignancy & $\begin{array}{l}415 \\
(7.6)\end{array}$ & $151(7.0)$ & $149(7.8)$ & $42(6.6)$ & $63(9.6)$ & $8(10.1)$ & $2(8.7)$ & 0.27 \\
\hline \multicolumn{9}{|l|}{$\begin{array}{l}\text { Primary } \\
\text { diagnosis, n (\%) }\end{array}$} \\
\hline $\begin{array}{l}\text { Cardiovascular } \\
\text { disease }\end{array}$ & $\begin{array}{l}1615 \\
(29.6)\end{array}$ & $\begin{array}{l}626 \\
(29.0)\end{array}$ & $465(24.2)$ & $\begin{array}{l}244 \\
(38.7)\end{array}$ & $\begin{array}{l}249 \\
(37.8)\end{array}$ & $23(29.5)$ & $8(34.8)$ & $<0.001$ \\
\hline Renal disease & $\begin{array}{l}327 \\
(6.0)\end{array}$ & $114(5.3)$ & $111(5.8)$ & $50(7.9)$ & $40(6.1)$ & $11(14.1)$ & $1(4.3)$ & 0.009 \\
\hline $\begin{array}{l}\text { Infectious } \\
\text { disease }\end{array}$ & $\begin{array}{l}1332 \\
(24.4)\end{array}$ & $\begin{array}{l}309 \\
(14.3)\end{array}$ & $581(30.3)$ & $\begin{array}{l}127 \\
(20.1)\end{array}$ & $\begin{array}{l}284 \\
(43.2)\end{array}$ & $28(35.9)$ & $3(13.0)$ & $<0.001$ \\
\hline $\begin{array}{l}\text { Gastrointestinal } \\
\text { disease }\end{array}$ & $\begin{array}{l}639 \\
(11.7)\end{array}$ & $\begin{array}{l}270 \\
(12.5)\end{array}$ & 209 (10.9) & $\begin{array}{l}82 \\
(13.0)\end{array}$ & 70 (10.6) & $8(10.3)$ & $0(0.0)$ & 0.18 \\
\hline $\begin{array}{l}\text { Hematologic } \\
\text { disease }\end{array}$ & $\begin{array}{l}188 \\
(3.4)\end{array}$ & $52(2.4)$ & $62(3.2)$ & $24(3.8)$ & $40(6.1)$ & $9(11.5)$ & $1(4.3)$ & $<0.001$ \\
\hline $\begin{array}{l}\text { Pulmonary } \\
\text { disease }\end{array}$ & $\begin{array}{l}1171 \\
(21.4)\end{array}$ & 189 (8.8) & $638(33.2)$ & $57(9.0)$ & $\begin{array}{l}274 \\
(41.6)\end{array}$ & $8(10.3)$ & $5(21.7)$ & $<0.001$ \\
\hline $\begin{array}{l}\text { Neurological } \\
\text { disease }\end{array}$ & $\begin{array}{l}565 \\
(10.3)\end{array}$ & $184(8.5)$ & $277(14.4)$ & $29(4.6)$ & $68(10.3)$ & $5(6.4)$ & $2(8.7)$ & $<0.001$ \\
\hline $\begin{array}{l}\text { Rheumatologic } \\
\text { disease }\end{array}$ & $\begin{array}{l}94 \\
(1.7)\end{array}$ & $25(1.2)$ & $32(1.7)$ & $11(1.7)$ & $23(3.5)$ & $2(2.6)$ & $1(4.3)$ & 0.004 \\
\hline $\begin{array}{l}\text { Oncologic } \\
\text { disease }\end{array}$ & $\begin{array}{l}388 \\
(7.1)\end{array}$ & $139(6.4)$ & $157(8.2)$ & $31(4.9)$ & $54(8.2)$ & $4(5.1)$ & $3(13.0)$ & 0.031 \\
\hline $\begin{array}{l}\text { Surgical-related } \\
\text { disease }\end{array}$ & $\begin{array}{l}1006 \\
(18.4)\end{array}$ & $\begin{array}{l}494 \\
(22.9)\end{array}$ & 363 (18.9) & $\begin{array}{l}92 \\
(14.6)\end{array}$ & $42(6.4)$ & $10(12.8)$ & $5(21.7)$ & $<0.001$ \\
\hline $\begin{array}{l}\text { Metabolic } \\
\text { disease }\end{array}$ & $\begin{array}{l}242 \\
(4.4)\end{array}$ & $98(4.5)$ & $79(4.1)$ & $41(6.5)$ & $19(2.9)$ & $3(3.8)$ & $2(8.7)$ & 0.040 \\
\hline $\begin{array}{l}\text { SOFA score, } \\
\text { mean (SD) }\end{array}$ & $\begin{array}{l}5.2 \\
(3.4)\end{array}$ & $3.7(3.1)$ & $6.3(3.0)$ & $4.6(3.1)$ & $7.1(3.2)$ & $7.3(3.4)$ & $5.4(3.3)$ & $<0.001$ \\
\hline $\begin{array}{l}\text { Non } \\
\text { renal/respiratory } \\
\text { SOFA score, } \\
\text { mean (SD) }\end{array}$ & $\begin{array}{l}3.2 \\
(2.8)\end{array}$ & $1.8(2.3)$ & $4.2(2.5)$ & $2.0(2.3)$ & $5.4(3.0)$ & $5.3(3.1)$ & $5.0(3.2)$ & $<0.001$ \\
\hline
\end{tabular}




\begin{tabular}{|c|c|c|c|c|c|c|c|c|}
\hline $\begin{array}{l}\text { APACHE II, } \\
\text { mean (SD) }\end{array}$ & $\begin{array}{l}14.6 \\
(7.3)\end{array}$ & $11.7(7.2)$ & $17.1(6.5)$ & $\begin{array}{l}12.7 \\
(6.0)\end{array}$ & $19.1(6.3)$ & $15.9(5.4)$ & $12.8(4.6)$ & $<0.001$ \\
\hline $\begin{array}{l}\text { Time to AKI, } \\
\text { median (IQR), } \\
\text { days }\end{array}$ & $2[1,3]$ & - & - & $1[1,2]$ & $3[2,5]$ & $1[1,1]$ & $2[2,3]$ & $<0.001$ \\
\hline $\begin{array}{l}\text { Time to ARF, } \\
\text { median (IQR), } \\
\text { days }\end{array}$ & $1[1,1]$ & - & $1[1,1]$ & - & $1[1,1]$ & $2[2,4]$ & $2[2,3]$ & $<0.001$ \\
\hline Anemia, n (\%) & $\begin{array}{l}1631 \\
(29.8)\end{array}$ & $\begin{array}{l}628 \\
(29.1)\end{array}$ & $524(27.3)$ & $\begin{array}{l}209 \\
(33.1)\end{array}$ & $\begin{array}{l}234 \\
(35.6)\end{array}$ & 31 (39.2) & 5 (21.7) & $<0.001$ \\
\hline $\begin{array}{l}\text { Percent fluid } \\
\text { overload, mean } \\
\text { (SD) }\end{array}$ & $\begin{array}{l}12.4 \\
(26.1)\end{array}$ & $6.8(20.1)$ & $15.6(28.6)$ & $\begin{array}{l}10.1 \\
(22.7)\end{array}$ & $\begin{array}{l}17.8 \\
(30.6)\end{array}$ & $\begin{array}{l}15.4 \\
(22.0)\end{array}$ & $12.3(24.3)$ & $<0.001$ \\
\hline $\begin{array}{l}\text { Vasopressor, n } \\
(\%)\end{array}$ & $\begin{array}{l}2433 \\
(44.5)\end{array}$ & $\begin{array}{l}948 \\
(44.0)\end{array}$ & $811(42.2)$ & $\begin{array}{l}255 \\
(40.3)\end{array}$ & $\begin{array}{l}362 \\
(55.0)\end{array}$ & $46(58.2)$ & $11(47.8)$ & $<0.001$ \\
\hline
\end{tabular}

ICU, intensive care unit; UC, universal coverage; SS, social security; BMI, body mass index; DM, diabetes mellitus; CKD, chronic kidney disease; CAD, coronary artery disease; CVD, cerebrovascular disease; SOFA, sequential organ failure assessment; APACHE, Acute Physiology and Chronic Health Evaluation; AKI, acute kidney injury; ARF, acute respiratory failure.

Table 2

Clinical outcomes stratified by acute kidney injury and acute respiratory failure patterns

\begin{tabular}{|c|c|c|c|c|c|c|c|c|}
\hline & Overall & $\begin{array}{l}\text { No } \\
\text { AKI/ARF }\end{array}$ & $\begin{array}{l}\text { ARF } \\
\text { alone }\end{array}$ & $\begin{array}{l}\text { AKI } \\
\text { alone }\end{array}$ & $\begin{array}{l}\text { ARF } \\
\text { first }\end{array}$ & $\begin{array}{l}\text { AKI } \\
\text { first }\end{array}$ & $\begin{array}{l}\text { Concurrent } \\
\text { AKI-ARF }\end{array}$ & $\begin{array}{l}P- \\
\text { value }\end{array}$ \\
\hline $\mathrm{N}$ & 5468 & 2156 & 1920 & 632 & 658 & 79 & 23 & \\
\hline Hospital death, n (\%) & $\begin{array}{l}1373 \\
(25.1)\end{array}$ & $\begin{array}{l}268 \\
(12.4)\end{array}$ & $\begin{array}{l}605 \\
(31.5)\end{array}$ & $\begin{array}{l}92 \\
(14.6)\end{array}$ & $\begin{array}{l}349 \\
(53.0)\end{array}$ & $\begin{array}{l}43 \\
(54.4)\end{array}$ & $16(69.6)$ & $<0.001$ \\
\hline $\begin{array}{l}\text { Length of ICU stay (day), } \\
\text { median [IQR] }\end{array}$ & $3[2,6]$ & $2[2,3]$ & $\begin{array}{l}4[3, \\
8]\end{array}$ & $\begin{array}{l}3[2 \\
5]\end{array}$ & $\begin{array}{l}7[4 \\
14]\end{array}$ & $5[4,8]$ & $5[4,7]$ & $<0.001$ \\
\hline $\begin{array}{l}\text { Length of hospital stay } \\
\text { (day), median [IQR] }\end{array}$ & $\begin{array}{l}9[5, \\
15]\end{array}$ & $7[4,11]$ & $\begin{array}{l}11[6, \\
20]\end{array}$ & $\begin{array}{l}8[5, \\
14]\end{array}$ & $\begin{array}{l}14[7, \\
29]\end{array}$ & $\begin{array}{l}10.5[5, \\
18]\end{array}$ & $9[5,17.5]$ & $<0.001$ \\
\hline $\begin{array}{l}\text { Total ventilator day, median } \\
\text { [IQR] }\end{array}$ & $0[0,3]$ & - & $\begin{array}{l}3[1 \\
6]\end{array}$ & - & $\begin{array}{l}5[3 \\
12]\end{array}$ & $2[1,5]$ & $3[1.5,4]$ & $<0.001$ \\
\hline $\begin{array}{l}\text { Ventilator free day, median } \\
\text { [IQR] }\end{array}$ & $\begin{array}{l}7[3, \\
12]\end{array}$ & $7[4,11]$ & $\begin{array}{l}6[2 \\
14]\end{array}$ & $\begin{array}{l}8[5 \\
14]\end{array}$ & $\begin{array}{l}6[1 \\
15.25]\end{array}$ & $\begin{array}{l}6.5[2 \\
13.75]\end{array}$ & $5[2.5,12.5]$ & $<0.001$ \\
\hline $\begin{array}{l}\text { Renal recovery at discharge, } \\
\mathrm{n}(\%)\end{array}$ & $\begin{array}{l}269 \\
(19.3)\end{array}$ & - & - & $\begin{array}{l}125 \\
(19.8)\end{array}$ & $\begin{array}{l}127 \\
(19.3)\end{array}$ & 15 (19) & $2(8.7)$ & 0.62 \\
\hline
\end{tabular}

ICU, intensive care unit.

Table 3

Risk factors for in-hospital mortality 


\begin{tabular}{|c|c|c|c|c|}
\hline Variables & Unadjusted OR (95\% Cl) & P-value & $\begin{array}{l}\text { Adjusted } \\
\text { OR }(95 \% \mathrm{Cl})\end{array}$ & P-value \\
\hline \multicolumn{5}{|l|}{ AKI-ARF pattern } \\
\hline No AKI/ARF & Reference & & Reference & \\
\hline ARF alone & $3.24(2.76-3.81)$ & $<0.001$ & 4.29 (2.97-6.19) & $<0.001$ \\
\hline AKI alone & $1.2(0.93-1.54)$ & 0.16 & $2.85(1.86-4.39)$ & $<0.001$ \\
\hline ARF first & 7.96 (6.52-9.72) & $<0.001$ & $13.45(9-20.1)$ & $<0.001$ \\
\hline AKI first & $8.41(5.31-13.4)$ & $<0.001$ & $10.91(5.43-21.9)$ & $<0.001$ \\
\hline Concurrent AKI-ARF & $16.1(6.81-42.22)$ & $<0.001$ & 52.01 (16.86-160.4) & $<0.001$ \\
\hline Age, 10 years & 1.04 (1.01-1.08) & 0.014 & $0.97(0.92-1.04)$ & 0.41 \\
\hline Female & $1.01(0.89-1.14)$ & 0.89 & - & - \\
\hline \multicolumn{5}{|l|}{ Hospital type } \\
\hline Provincial hospital & Reference & & Reference & \\
\hline Regional hospital & $1.1(0.89-1.35)$ & 0.38 & $0.86(0.35-2.16)$ & 0.76 \\
\hline University hospital & 1.63 (1.39-1.93) & $<0.001$ & $1.39(0.6-3.21)$ & 0.44 \\
\hline \multicolumn{5}{|l|}{ ICU type } \\
\hline Surgical ICU & Reference & & Reference & \\
\hline Mixed ICU & $11.54(6.61-22.53)$ & $<0.001$ & 8.69 (1.81-41.63) & 0.007 \\
\hline Medical ICU & $8.13(4.64-15.89)$ & $<0.001$ & $5.66(1.26-25.48)$ & 0.024 \\
\hline \multicolumn{5}{|l|}{ Reimbursement } \\
\hline UC, SS & Reference & & Reference & \\
\hline Government & $0.97(0.82-1.13)$ & 0.67 & $1.15(0.92-1.46)$ & 0.22 \\
\hline Self pay & $1.79(1.55-2.06)$ & $<0.001$ & $0.93(0.6-1.44)$ & 0.75 \\
\hline \multicolumn{5}{|l|}{ BMI } \\
\hline Underweight & $1.2(0.99-1.46)$ & 0.059 & $1.3(0.98-1.74)$ & 0.07 \\
\hline Normal & Reference & & Reference & \\
\hline Overweight & $0.8(0.67-0.95)$ & 0.01 & $0.82(0.63-1.08)$ & 0.16 \\
\hline Obese & $0.64(0.44-0.9)$ & 0.014 & $0.62(0.38-1.03)$ & 0.06 \\
\hline \multicolumn{5}{|l|}{ Comorbidity } \\
\hline Hypertension & $1.11(0.98-1.26)$ & 0.11 & $0.93(0.75-1.16)$ & 0.53 \\
\hline DM & 1.59 (1.38-1.82) & $<0.001$ & $1.25(0.98-1.58)$ & 0.07 \\
\hline CKD & $1.14(0.89-1.45)$ & 0.28 & - & - \\
\hline CAD & $0.8(0.62-1.02)$ & 0.08 & $0.95(0.68-1.35)$ & 0.79 \\
\hline
\end{tabular}




\begin{tabular}{|lllll|} 
CVD & $0.81(0.57-1.11)$ & 0.20 & - & - \\
\hline Malignancy & $0.97(0.77-1.22)$ & 0.80 & - & - \\
\hline Anemia & $1.88(1.65-2.14)$ & $<0.001$ & $1.22(0.98-1.51)$ & 0.07 \\
\hline Vasopressor & $3.38(2.97-3.84)$ & $<0.001$ & $2.9(2.31-3.63)$ & $<0.001$ \\
\hline APACHE II & $1.15(1.14-1.16)$ & $<0.001$ & $1.09(1.07-1.11)$ & $<0.001$ \\
\hline Fluid overload & $1.73(1.48-2.01)$ & $<0.001$ & $1.43(1.15-1.79)$ & 0.002 \\
\hline
\end{tabular}

AKI, acute kidney injury; ARF, acute respiratory failure; ICU, intensive care unit; UC, universal coverage; SS, social security; DM, diabetes mellitus; CKD, chronic kidney disease; CAD, coronary artery disease; CVD, cerebrovascular disease; APACHE, Acute Physiology and Chronic Health Evaluation.

\section{Table 4}

Multivariable analyses examining interactions between acute kidney injury and acute respiratory failure patterns and risk factors associated with in-hospital mortality

\begin{tabular}{|llll|}
\hline Interaction of AKI-ARF pattern with: & X2 & df & P-value \\
\hline Age, increase by 10 years & 8.8 & 5 & 0.12 \\
\hline Gender & 4.6 & 5 & 0.47 \\
\hline Hospital type & 20.1 & 10 & 0.028 \\
\hline ICU type & 15.1 & 9 & 0.09 \\
\hline Reimbursement & 11.2 & 9 & 0.27 \\
\hline BMI & 15.6 & 15 & 0.41 \\
\hline Hypertension & 8.9 & 5 & 0.11 \\
\hline DM & 0.9 & 5 & 0.97 \\
\hline CKD & 4.9 & 5 & 0.43 \\
\hline CAD & 0.5 & 4 & 0.97 \\
\hline CVD & 8.1 & 5 & 0.15 \\
\hline Malignancy & 3.6 & 5 & 0.61 \\
\hline Anemia & 5.1 & 5 & 0.40 \\
\hline Vasopressor & 12.0 & 5 & 0.035 \\
\hline APACHE II & 10.1 & 5 & 0.07 \\
\hline Fluid overload & 8.9 & 5 & 0.12 \\
\hline
\end{tabular}

ICU, intensive care unit; DM, diabetes mellitus; CKD, chronic kidney disease; CAD, coronary artery disease; CVD, cerebrovascular disease; APACHE, Acute Physiology and Chronic Health Evaluation.

\section{Figures}




\section{Figure 1}

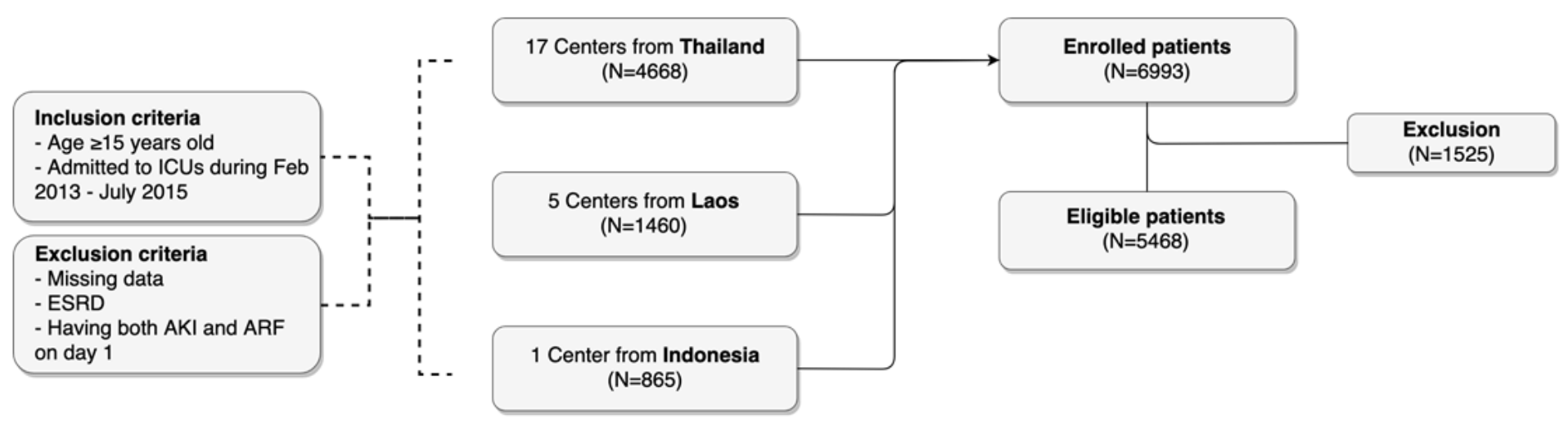

Figure 1

Study flow
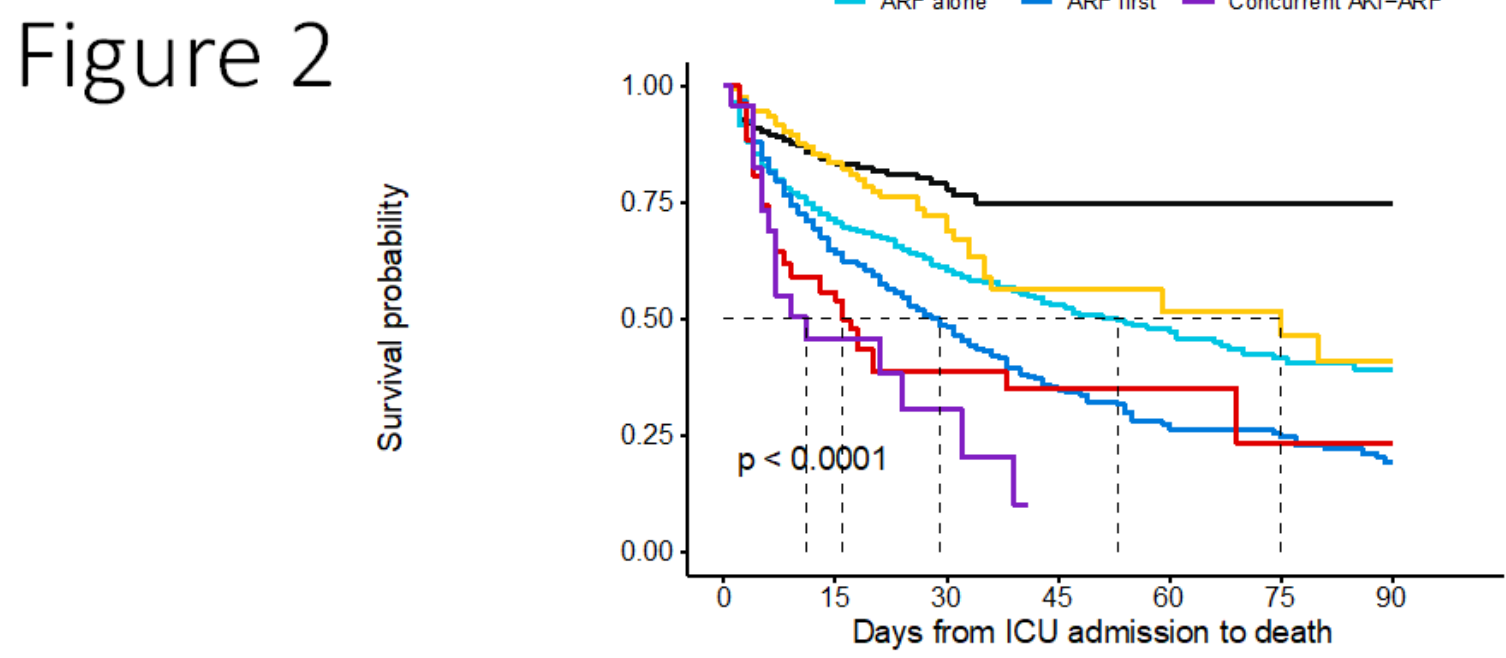

Number at risk

\begin{tabular}{|c|c|c|c|c|c|c|c|}
\hline \multirow{7}{*}{$\begin{array}{r}\text { No AKI/ARF } \\
\text { ARF alone } \\
\text { AKI alone } \\
\text { ARF first } \\
\text { AK first } \\
\text { Concurrent AKI-ARF }\end{array}$} & 2154 & 280 & 63 & 22 & 11 & 7 & 5 \\
\hline & 1920 & 685 & 273 & 125 & 69 & 38 & 28 \\
\hline & 628 & 152 & 45 & 20 & 11 & 10 & 5 \\
\hline & 657 & 324 & 155 & 75 & 43 & 31 & 20 \\
\hline & 78 & 30 & 11 & 6 & 5 & 2 & 2 \\
\hline & 23 & 6 & 4 & 0 & 0 & 0 & 0 \\
\hline & 0 & 15 & 30 & 45 & 60 & 75 & 90 \\
\hline
\end{tabular}

Figure 2 
Kaplan-Meier curve for survival after intensive care unit admission by acute kidney injury and acute respiratory failure patterns. ICU, intensive care unit; AKI, acute kidney injury; ARF, acute respiratory failure.

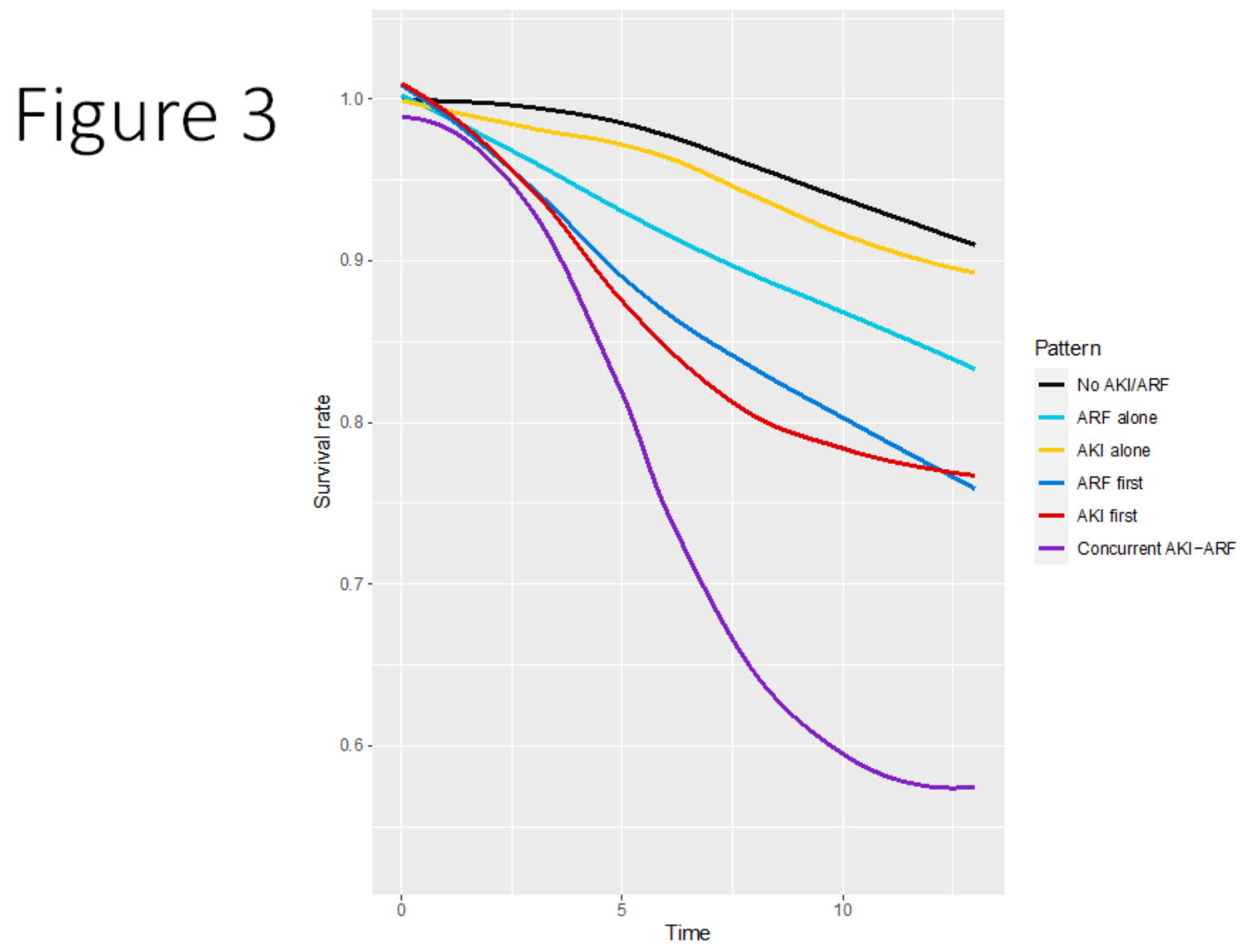

\section{Figure 3}

Adjusted survival by acute kidney injury and acute respiratory failure patterns. Survival differences are highly significant overall $(P<0.001)$. All pairwise comparisons are also significant except "No AKI/ARF" versus "AKI alone" $(P=0.93)$ and "AKI first" versus "ARF first" ( $P=0.22)$. AKI, acute kidney injury; ARF, acute respiratory failure.

\section{Supplementary Files}

This is a list of supplementary files associated with this preprint. Click to download.

- Supplementarydata.docx 